\section{Commentary: The wizard of OS: Is overall survival better after sublobar resection versus stereotactic radiation or ablation?}

\author{
Jules Lin, MD, FACS, FCCP
}

In this issue, $\mathrm{Wu}$ and colleagues ${ }^{1}$ report better survival with sublobar resection versus stereotactic radiation (SBRT) or ablation in patients with clinical stage I non-small cell lung cancer. Strengths include the large number of patients and propensity matching. All patients had a histologic diagnosis, which was an issue with previous studies, including the ROSEL (Radiosurgery or Surgery for Operable Early Lung Cancer Study) SBRT versus lobectomy trial, in which histologic confirmation was not required, and at least 1 patient had benign disease after surgery. ${ }^{2}$ Although resection has been standard for early-stage non-small cell lung cancer, surgery is being increasingly challenged by SBRT, highlighting the potential significance of these results. However, due to limitations of the National Cancer Database, important data points are missing from the analysis, making the results more difficult to interpret.

Although overall survival was less with SBRT and ablation, cancer-specific survival was not available. These patients often have significant comorbidities and limited function, making them nonoperative candidates and increasing the risk of noncancer causes of mortality with a substantial risk of selection bias. Ackerson and colleagues $^{3}$ found greater overall survival after sublobar resection compared with SBRT but no difference in cancer-specific survival. Data on pulmonary function, histologic subtypes (adenocarcinoma in situ, minimally invasive adenocarcinoma, or lepidic predominant lesions), and computed tomography imaging (ground-glass or partsolid lesions) were also missing.

From the Section of Thoracic Surgery, Department of Surgery, University of Michigan Medical Center, Ann Arbor, Mich.

Disclosures: Author has nothing to disclose with regard to commercial support.

Received for publication Dec 12, 2019; revisions received Dec 12, 2019; accepted for publication Dec 15, 2019; available ahead of print Jan 7, 2020.

Address for reprints: Jules Lin, MD, FACS, FCCP, Section of Thoracic Surgery, 1500 E. Medical Center Dr, 2120TC/5344, Ann Arbor, MI $48109-5344$ (E-mail: juleslin@umich.edu).

J Thorac Cardiovasc Surg 2020;160:1358-9

$0022-5223 / \$ 36.00$

Copyright (c) 2020 by The American Association for Thoracic Surgery

https://doi.org/10.1016/j.jtcvs.2019.12.061

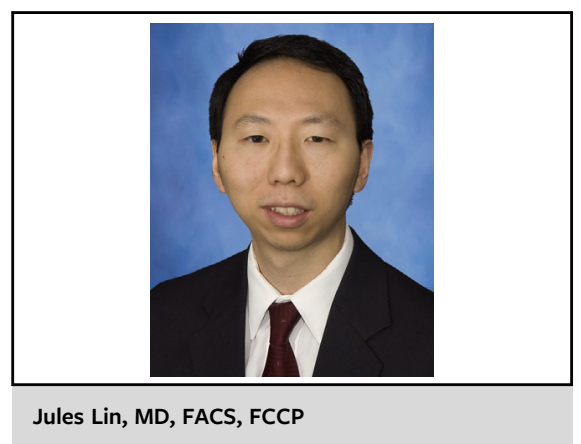

CENTRAL MESSAGE

The authors report better sur-

vival with sublobar resection

versus stereotactic radiation or

ablation, although data in the

National Cancer Database are

limited and future prospective

studies are needed.

In evaluating sublobar resection, segmentectomy and wedge resection are not equivalent, and segmental lymph nodes are not removed with nonanatomical wedge resection. Although both were associated with improved survival here, a Surveillance, Epidemiology, and End Results study of early-stage lung cancer found SBRT was associated with similar survival to wedge resection but worse outcomes compared with segmentectomy. ${ }^{4}$ Dai and colleagues ${ }^{5}$ also found that optimal lymph node evaluation was important for accurate staging in stage I lung cancer, and in the current study, $4.4 \%$ of patients with clinical stage I were upstaged after surgery.

Randomized trials comparing SBRT and lobectomy have been slow to accrue, with both the ROSEL (NCT00687986) and STARS (Randomized Study to Compare CyberKnife to Surgical Resection in Stage I Non-Small Cell Lung Cancer; NCT00840749) trials closing early. Although Chang and colleagues performed a pooled analysis of these 2 trials and reported a significantly lower overall 3-year survival with lobectomy than SBRT, there were significant issues, with only 58 patients recruited from 38 institutions. ${ }^{6}$ In addition, $11 \%$ of patients assigned to surgery did not undergo lobectomy, and histologic confirmation was not required in the ROSEL trial.

Although lobectomy has been the standard approach for early-stage lung cancer, with challenges from SBRT and ablation, it is clear that we are no longer in Kansas. We await the results of randomized trials comparing sublobar resection and lobectomy (CALGB 140503 and JCOG 
0802), and although further prospective trials are needed with limitations in the National Cancer Database, as we continue our journey to meet the Wizard of OS (overall survival) with the tin man and the scarecrow, we as surgeons must emphasize, like the lion finding his courage, the importance of systematic lymphadenectomy, the use of minimally invasive approaches to minimize morbidity, and the use of segmentectomy when appropriate on our walk down the yellow brick road.

\section{References}

1. Wu J, Bai HX, Chan L, Su C, Zhang PJ, Yang L, et al. Sublobar resection compared with stereotactic body radiation therapy and ablation for early stage non-small cell lung cancer: a National Cancer Data Base study. J Thorac Cardiovasc Surg. 2020; 160:1350-7.e11.
2. Hurkmans CW, Cuijpers JP, Lagerwaard FJ, Widder J, van der Heide UA, Schuring D, et al. Recommendations for implementing stereotactic radiotherapy in peripheral stage IA non-small cell lung cancer: report from the Quality Assurance Working Party of the randomised phase III ROSEL study. Radiat Oncol. 2009; $4: 1$.

3. Ackerson BG, Tong BC, Hong JC, Gu L, Chino J, Trotter JW, et al. Stereotactic body radiation therapy versus sublobar resection for stage I NSCLC. Lung Cancer. 2018;125:185-91.

4. Ezer N, Veluswamy RR, Mhango G, Rosenzweig KE, Powell CA, Wisnivesky JP. Outcomes after stereotactic body radiotherapy versus limited resection in older patients with early-stage lung cancer. J Thorac Oncol. 2015; 10:1201-6.

5. Dai J, Liu M, Yang Y, Li Q, Song N, Rocco G, et al. Optimal lymph node examination and adjuvant chemotherapy for stage I lung cancer. J Thorac Oncol. 2019; 14:1277-85.

6. Chang JY, Senan S, Paul MA, Mehran RJ, Louie AV, Balter P, et al. Stereotactic ablative radiotherapy versus lobectomy for operable stage I non-small-cell lung cancer: a pooled analysis of two randomised trials. Lancet Oncol. 2015;16:630-7.
See Article page 1350.

\section{Commentary: To wedge or not to wedge}

\author{
Chadrick E. Denlinger, MD
}

The standard treatment for early-stage non-small cell lung cancer remains a lobectomy with lymph node dissection, but this precedent hangs entirely on a single prospective randomized study published 25 years ago. ${ }^{1}$ A complete lobectomy may not offer an oncologic advantage for small peripheral tumors, and a lobectomy may not be feasible because of prohibitive cardiopulmonary reserve. For patients intolerant of a lobectomy, it remains unclear what alternative provides the best outcome. Sublobar resection and stereotactic body radiotherapy (SBRT) represent the 2 most frequent alternatives to lobectomy for early-stage lung cancer. Three prospective randomized trials comparing resection with SBRT have been attempted, but each closed after failing to accrue patients. Preliminary

\footnotetext{
From the Division of Cardiothoracic Surgery, Medical University of South Carolina, Charleston, SC.

Disclosures: Author has nothing to disclose with regard to commercial support.

Received for publication Dec 23, 2019; accepted for publication Dec 23, 2019; available ahead of print Jan 11, 2020.

Address for reprints: Chadrick E. Denlinger, MD, Division of Cardiothoracic Surgery, Department of Surgery, Medical University of South Carolina, 114 Doughty St,

Charleston, SC 29425 (E-mail: denlinge@musc.edu).

J Thorac Cardiovasc Surg 2020;160:1359-60

$0022-5223 / \$ 36.00$

Copyright (c) 2020 by The American Association for Thoracic Surgery

https://doi.org/10.1016/j.jtcvs.2019.12.087
}

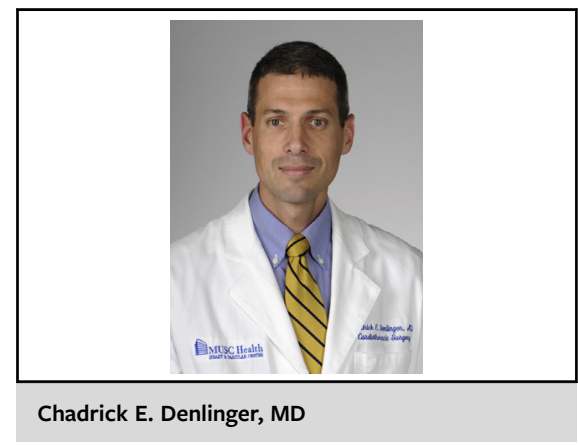

CENTRAL MESSAGE

A retrospective review of a large administrative database suggests that the most effective alternative to lobectomy for early-stage lung cancer is a sublobar resection followed by SBRT and thermal ablation.

data from the ACOSOG Z40099 trial have not been reported, but a pooled analysis of the STARS (Randomized Study to Compare CyberKnife to Surgical Resection in Stage I Non-Small Cell Lung Cancer) and ROSEL (Trial of Either Surgery or Stereotactic Radiotherapy for Early Stage [IA] Lung Cancer) trials that enrolled patients with cT1-T2aN0M0 lung cancers show similar recurrence-free survival rates for surgical and SBRT patients at 3 years. ${ }^{2}$ Thus, there are no prospective data comparing the efficacy 